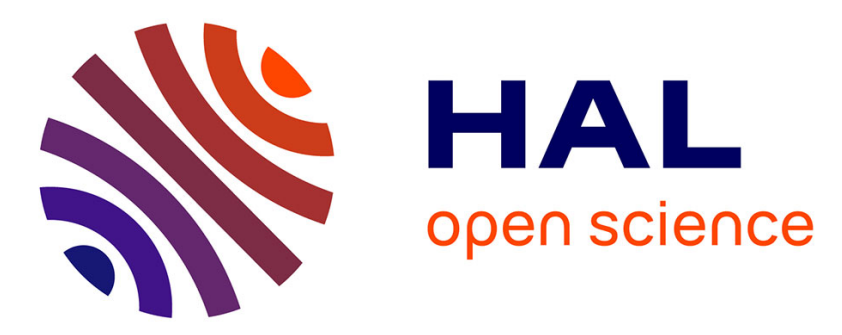

\title{
Supramolecular gel strategy-based nanomaterials with room temperature spin transition
}

Xuan An, Wan Fang, Zhaolong Wang, Kaiqiang Liu, Liping Ding, Junxia Peng, Taihong Liu, Haonan Peng, Lionel Salmon, Yu Fang

\section{To cite this version:}

Xuan An, Wan Fang, Zhaolong Wang, Kaiqiang Liu, Liping Ding, et al.. Supramolecular gel strategybased nanomaterials with room temperature spin transition. Colloids and Surfaces A: Physicochemical and Engineering Aspects, 2021, 612, pp.126016. 10.1016/j.colsurfa.2020.126016 . hal-03179202

\section{HAL Id: hal-03179202 \\ https://hal.science/hal-03179202}

Submitted on 24 Mar 2021

HAL is a multi-disciplinary open access archive for the deposit and dissemination of scientific research documents, whether they are published or not. The documents may come from teaching and research institutions in France or abroad, or from public or private research centers.
L'archive ouverte pluridisciplinaire HAL, est destinée au dépôt et à la diffusion de documents scientifiques de niveau recherche, publiés ou non, émanant des établissements d'enseignement et de recherche français ou étrangers, des laboratoires publics ou privés. 


\section{Supramolecular gel strategy-based nanomaterials with room temperature spin transition}

Xuan An, ${ }^{\# a}$ Wan Fang, ${ }^{\# a}$ Zhaolong Wang, ${ }^{a}$ Kaiqiang Liu, ${ }^{a}$ Liping Ding, ${ }^{a}$ Junxia Peng, ${ }^{a}$ Taihong Liu, ${ }^{a}$ Haonan Peng, ${ }^{* a}$ Lionel Salmon*b and Yu Fang*a

${ }^{a}$ Key Laboratory of Applied Surface and Colloid Chemistry of Ministry of Education, School of Chemistry and Chemical Engineering, Shaanxi Normal University, Xi'an 710062, China

${ }^{\mathrm{b}}$ Laboratoire de Chimie de Coordination, CNRS UPR-8241 and Université de Toulouse, UPS, INP, F-31077 Toulouse, France

*Correspondence should be addressed.

Email:phn@snnu.edu.cn; yfang@ snnu.edu.cn; lionel.salmon@lcc-toulouse.fr

\section{Graphical Abstract}

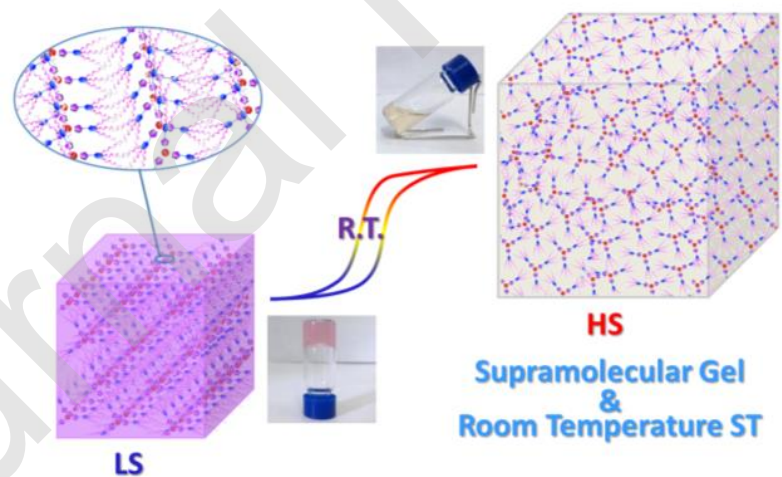

SCO nanomaterials with a hysteresis centered at room temperature fabricated based on supramolecular gel strategy is reported. 


\begin{abstract}
Novel $\left[\mathrm{Fe}(\mathrm{Rtrz})_{3}\right]\left(\mathrm{SO}_{3} \mathrm{CF}_{3}\right)_{2}$ based $\mathrm{SCO}$ nanomaterials were fabricated through the supramolecular gel strategy. By modifying the assembly conditions, surfactant or polymer-free SCO nanomaterial with different sizes and morphologies could be prepared. Furthermore, their spin crossover behavior was investigated by optical, magnetic and Mössbauer measurements. The spin transition features for the nanosized materials presented room temperature transition with a hysteresis loop, which could mainly be attributed to the intermolecular van der Waals interactions of tris(dodecyloxy)-benzamide introduced on the structure of $\left[\mathrm{Fe}(\mathrm{Rtrz})_{3}\right]\left(\mathrm{SO}_{3} \mathrm{CF}_{3}\right)_{2}$.
\end{abstract}

Keywords: spin crossover, thermochromism, self-assembly, gel

\title{
Introduction
}

Mobile electronics, the Internet, artificial intelligence, big data and high-performance computing have posed a major challenge on data storage and processing: the volume of digital information across the globe doubles every two years, which has reached 44 zettabytes $\left(4.4 \times 10^{10}\right.$ terabytes $)$ by 2020 . For information storage, the strategy based on the concept of molecular bistability that switches between two electronic states of a molecule in the same way as a binary switch is one of the most promising strategies among the competing candidates. A typical example of molecular bistability is the spin crossover (SCO) phenomenon, also called spin transition (ST) phenomenon. The two states of SCO materials, high spin (HS) and low spin (LS) states, can be converted by external stimuli such as temperature, light, pressure, magnetic field and/or inclusion of a guest molecule, ${ }^{1-3}$ which makes them a fascinating class of materials with potential applications in molecular electronics, ${ }^{4-6}$ sensors, ${ }^{7-9}$ molecular actuators, ${ }^{10-13}$ etc. The related characterization technology is diverse and advanced, ${ }^{14}$ which provides a solid foundation for the application of SCO materials. To satisfy these applications, it is of prominent importance to design and synthesize SCO materials with a size of nano-scale and room temperature spin transition. ${ }^{15,16}$ 
At present, several methods have been developed to prepare SCO nanomaterials,${ }^{17}$ including reverse micelle technique, ${ }^{18}$ polymer and biopolymer stabilization method ${ }^{19,20}$ and homogeneous acid medium technique. ${ }^{21,22}$ Nevertheless, it is still challenging to prepare SCO materials with controllable sizes and morphologies. Reverse micelle method was applied to synthesize NPs with different sizes through adjusting the surfactant concentrations, while the reproducibility is poor due to uncontrolled parameters. ${ }^{23}$ Moreover, owing to the strong matrix effect, the reverse micelle technique and polymer stabilization method will undoubtedly introduce excess surfactants or polymers on the surface of SCO materials, leading to a weakening of their SCO response. ${ }^{24,25} \mathrm{In}$ addition, there are only few reports about room temperature SCO materials, since it depends not only on the characteristic of SCO complexes but also on their molecular interactions. Such as hydrogen bonding ${ }^{26,27}$ or $\pi-\pi$ stacking interactions ${ }^{28,29}$ can achieve the cooperative SCO transitions. Within supramolecular gels, the gelators self-assemble ${ }^{30,31}$ into three-dimensional (3D) networked structures with different morphologies through noncovalent intermolecular interactions including hydrogen bonding, $\pi-\pi$ stacking, van der Waals, coordination, and other interactions. ${ }^{32}$ These special morphologies and interactions make supramolecular gels applicable in a wide range of areas. ${ }^{33,34}$ However, to our knowledge, there are only limited reports for the preparation of SCO nanomaterials by using the supramolecular gel strategy that could exhibit remarkable properties. ${ }^{35,36}$ Meanwhile, there is no report for the preparation of nanoparticles with different size and morphology through the supramolecular gel strategy.

Herein, the tris(dodecyloxy)-benzamide modified triazole SCO derivative $\left[\mathrm{Fe}(\mathrm{Rtrz})_{3}\right]\left(\mathrm{SO}_{3} \mathrm{CF}_{3}\right)_{2}$ was designed and synthesized. (Triazole)Fe(II) complexes are an important family of compounds that could exhibit switching properties at around room temperature. ${ }^{37,38}$ Through the modification of 4substituent on the triazole ligand and/or the choice of the counter-anion, the SCO characteristics of (triazole)Fe(II) complexes could be well modulated. ${ }^{39,40}$ In this work, the tris(dodecyloxy)-benzamide was chemically modified at the 4- 
substituent of the triazole ligand to improve the solubility in common organic solvents and the gelation ability of the SCO complex. Interestingly, by using the supramolecular gel strategy, surfactant/polymer-free SCO nanomaterials could be fabricated with as-synthesized $\left[\mathrm{Fe}(\mathrm{Rtrz})_{3}\right]\left(\mathrm{SO}_{3} \mathrm{CF}_{3}\right)_{2}$ complex. The size and morphology of the SCO nanomaterials could be controlled by varying the concentration, the solvent and the temperature. Moreover, their SCO behavior was studied by optical, magnetic and Mössbauer measurements.

\section{Results and discussion}

The triazole derivative $\left[\mathrm{Fe}(\mathrm{Rtrz})_{3}\right]\left(\mathrm{SO}_{3} \mathrm{CF}_{3}\right)_{2}$ (Scheme 1) was prepared according to the synthesis route (Scheme S1, ESI $\dagger$ ), the composition of which was verified by IR spectra and elemental analysis (see the ESI $\uparrow$ for details). Unfortunately, in this family of 'Fe-triazole' coordination polymers, crystals structures are very difficult to obtain. ${ }^{41}$ To study the self-assembly property of as-synthesized compound, the gelation behavior of $\left[\mathrm{Fe}(\mathrm{Rtrz})_{3}\right]\left(\mathrm{SO}_{3} \mathrm{CF}_{3}\right)_{2}$ in 18 organic solvents was investigated systematically, as shown in Table 1. It was found that the compound exhibited good solubility in chlorohydrocarbon and aromatic solvents. Interestingly, $\left[\mathrm{Fe}(\mathrm{R} \operatorname{trz})_{3}\right]\left(\mathrm{SO}_{3} \mathrm{CF}_{3}\right)_{2}$ could form robust gel in alkane solvents: $n$-hexane, $n$-heptane and cyclohexane. Critical gelation concentrations (CGCs) of the three gels $(w / v)$ were $0.4 \%$ for $n$-hexane $\left(T_{\text {gel }}=\right.$ $283 \mathrm{~K}), 0.4 \%$ for $n$-heptane $\left(T_{\text {gel }}=283 \mathrm{~K}\right)$ and $0.7 \%$ for cyclohexane $\left(T_{\text {gel }}=283\right.$ $\mathrm{K})$, indicating the excellent gelation ability of the compound. Furthermore, the gel-sol phase transitions of $\left[\mathrm{Fe}(\mathrm{Rtrz})_{3}\right]\left(\mathrm{SO}_{3} \mathrm{CF}_{3}\right)_{2}$ in $n$-heptane $(2 \% w / v)$ triggered by heating and cooling were depicted in Fig. 1. It could form gel at low temperature (bellow $283 \mathrm{~K}$ ). When the temperature was increased slowly to $293 \mathrm{~K}$, the pink gel became gradually a pale pink homogeneous sol, and then
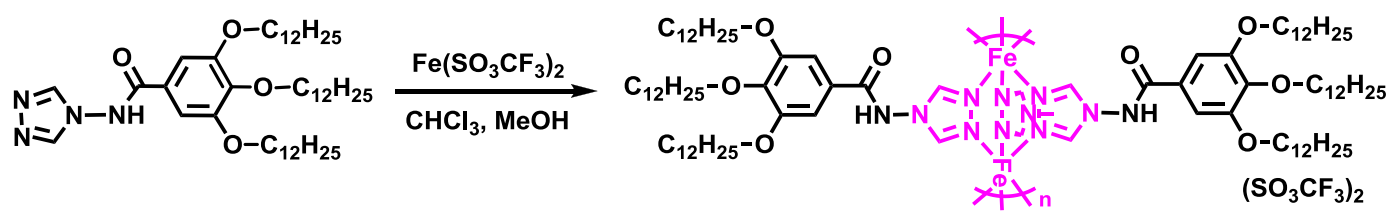

Scheme 1 The synthetic route for target $\left[\mathrm{Fe}(\mathrm{Rtrz})_{3}\right]\left(\mathrm{SO}_{3} \mathrm{CF}_{3}\right)_{2}$. 


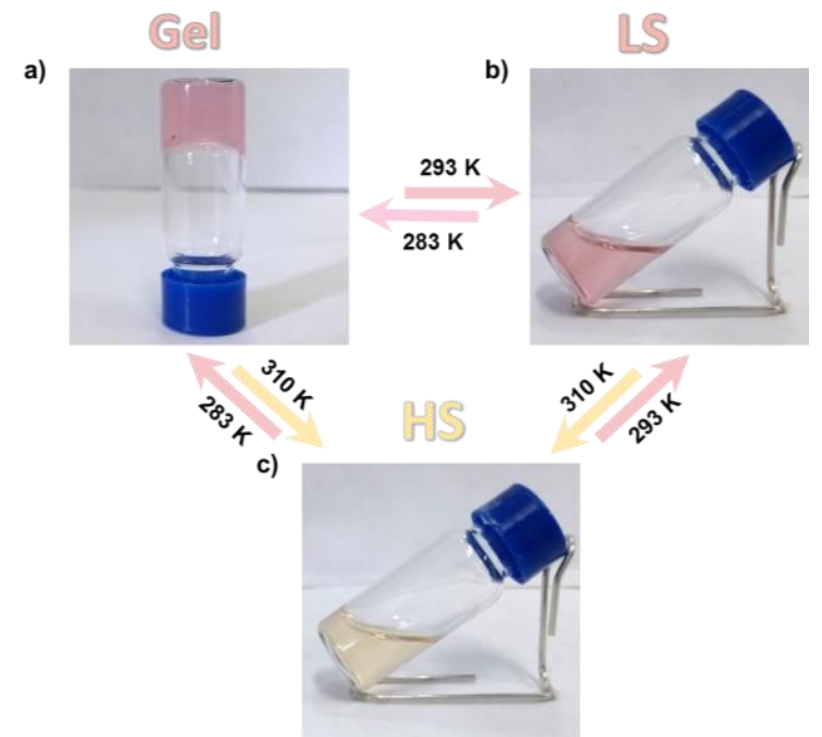

Fig. 1 The gel-sol phase transitions of single solvent gel ( $n$-heptane) of $\left[\mathrm{Fe}(\mathrm{Rtrz})_{3}\right]\left(\mathrm{SO}_{3} \mathrm{CF}_{3}\right)_{2}$ in response to heat trigger. (a) $2 \% w / v$ at $283 \mathrm{~K}$ (gel); (b) $2 \% w / v$ at $293 \mathrm{~K}$ (sol); (c) $2 \% w / v$ at $310 \mathrm{~K}$ (solution).

turned to a pale yellow transparent solution at $310 \mathrm{~K}$. These results indicated that the gel-sol phase transition temperature in alkane solvents could be ascribed to the introduction of tris(dodecyloxy)-benzamide, which was an important building block of self-assembling systems. The van der Waals interactions between the three long-chain alkane residues and alkane solvents might facilitate the formation of gel. It was reported that the supramolecular aggregation behavior of tris(dodecyloxy)-benzamide was extremely sensitive to the polarity of the environment, ${ }^{42}$ which could explain the differential selfassembly behavior of $\left[\mathrm{Fe}(\mathrm{Rtrz})_{3}\right]\left(\mathrm{SO}_{3} \mathrm{CF}_{3}\right)_{2}$ in varied organic solvents.

Supramolecular gels are usually constructed by 3D networked structures of the gelators, the formation of which could be modulated by the concentrations of the gelators and the temperature of the solution. Therefore, the self-assembly behavior of $\left[\mathrm{Fe}(\mathrm{Rtrz})_{3}\right]\left(\mathrm{SO}_{3} \mathrm{CF}_{3}\right)_{2}$ in alkane solvents under different concentrations and temperatures was investigated in detail. As shown from the transmission electron microscope (TEM) images in Fig. 2, it was lucky to find that the microscopic morphologies of $\left[\mathrm{Fe}(\mathrm{Rtrz})_{3}\right]\left(\mathrm{SO}_{3} \mathrm{CF}_{3}\right)_{2}$ aggregates could be well controlled by varying the solvents and concentrations at $283 \mathrm{~K}$. Fiber network structure was formed by the self-assembly of $\left[\mathrm{Fe}(\mathrm{Rtrz})_{3}\right]\left(\mathrm{SO}_{3} \mathrm{CF}_{3}\right)_{2}$ in $n$-hexane solution with a concentration of $0.1 \% \mathrm{w} / \mathrm{v}$ (sample 1). Increasing the concentration of $\left[\mathrm{Fe}(\mathrm{Rtrz})_{3}\right]\left(\mathrm{SO}_{3} \mathrm{CF}_{3}\right)_{2}$ from $0.1 w / v$ to $0.3 \% w / v$, the aggregates 
changed to lamellar shape with obvious fringes. $\left[\mathrm{Fe}(\mathrm{Rtrz})_{3}\right]\left(\mathrm{SO}_{3} \mathrm{CF}_{3}\right)_{2}$ selfassembled in $0.1 \% \mathrm{w} / \mathrm{v} n$-heptane solution to form well organized cubic morphology with a size of hundreds of nanometers (sample 2). When the concentration of $\left[\mathrm{Fe}(\mathrm{Rtrz})_{3}\right]\left(\mathrm{SO}_{3} \mathrm{CF}_{3}\right)_{2}$ increases from $0.1 \% \mathrm{w} / v$ to $0.3 \% \mathrm{w} / v$, crude fiber structure appeared. In addition, the cubic structure was also shown in the samples of $\left[\mathrm{Fe}(\mathrm{Rtrz})_{3}\right]\left(\mathrm{SO}_{3} \mathrm{CF}_{3}\right)_{2}$ in cyclohexane solution at both $0.1 \%$ $w / v$ (sample 3 ) and $0.3 \% w / v$ concentrations. To the best of our knowledge, this was the first case that cubic morphology was formed by the $\mathrm{Fe}(\mathrm{II})$-triazole derivatives. Temperature is also an important factor that affects the selfassembly behavior of the gelators. The morphology of [ $\left.\mathrm{Fe}(\mathrm{Rtrz})_{3}\right]\left(\mathrm{SO}_{3} \mathrm{CF}_{3}\right)_{2}$ assemblies changed a lot as the temperature increased from $283 \mathrm{~K}$ (Fig. 2) to 288 K (Fig. S8). Uniform structures formed at $283 \mathrm{~K}$ disappeared, instead, large and irregular aggregates were generated. This phenomenon could be explained that the molecules might slowly transform into equilibrium aggregation state of the uniform nanostructure at low temperature. The TEM particle size distribution of $\left[\mathrm{Fe}(\mathrm{Rtrz})_{3}\right]\left(\mathrm{SO}_{3} \mathrm{CF}_{3}\right)_{2}$ assembled at $283 \mathrm{~K}$ (Fig. S9) shows that the size of the square morphology is about 200-400 nm. However, 
when the temperature was increased, the molecules tended to an increased disorder, and TEM images showed the existence of aggregate structures with uneven and irregular size. ${ }^{43}$ In addition, we have also studied assembly behavior of $\left[\mathrm{Fe}(\mathrm{Rtrz})_{3}\right]\left(\mathrm{SO}_{3} \mathrm{CF}_{3}\right)_{2}$ in poor solvents (such as ethyl acetate), but no nanomaterials with regular morphologies have been obtained (Fig. S10).

For the SCO complexes, drastic color change often occurs accompanying the spin transition, since the changes in the bond length between the metal center and the ligand could affect the electronic state and symmetry of metal complex. Therefore, the $\mathrm{SCO}$ phenomenon of $\left[\mathrm{Fe}(\mathrm{Rtrz})_{3}\right]\left(\mathrm{SO}_{3} \mathrm{CF}_{3}\right)_{2}$ was monitored by the variable-temperature UV-Vis spectra and the optical reflectance measurements.

Fig. 3 presents the variable-temperature UV-Vis of the complex in $n$-heptane. At a low temperature of $293 \mathrm{~K}$, it was observed that the ${ }^{1} \mathrm{~A}-{ }^{1} \mathrm{~T}$ absorption of $\left[\mathrm{Fe}(\mathrm{Rtrz})_{3}\right]\left(\mathrm{SO}_{3} \mathrm{CF}_{3}\right)_{2}$ centered at $520 \mathrm{~nm}$. Switching from $293 \mathrm{~K}$ (LS state) to $343 \mathrm{~K}$ (HS state), it led to the bleaching of the absorption band at $520 \mathrm{~nm}$. This process was reversible, and the absorption centered at $520 \mathrm{~nm}$ would recover
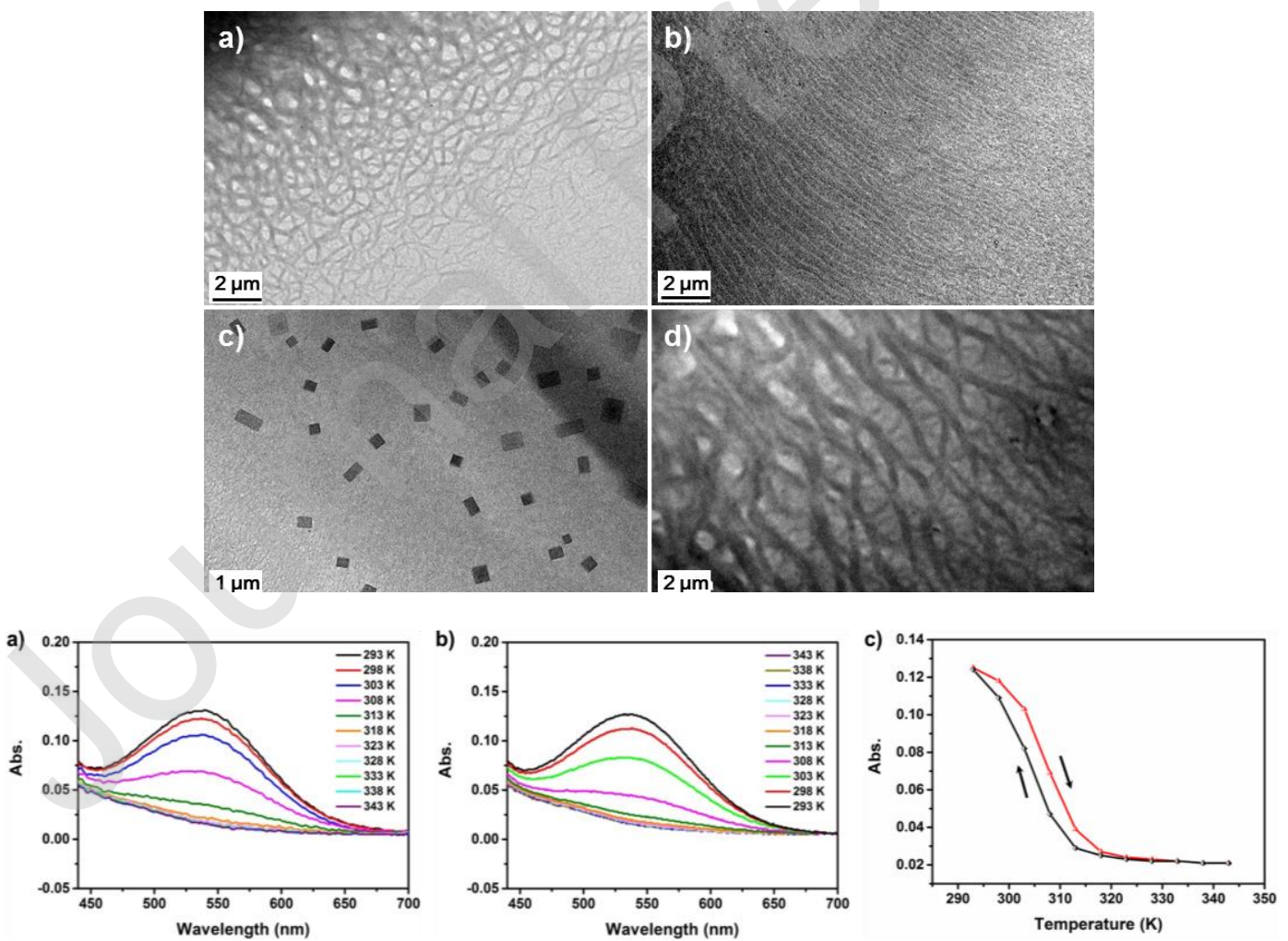

Fig. 3 UV-Vis absorption spectra of $\left[\mathrm{Fe}(\mathrm{Rtrz})_{3}\right]\left(\mathrm{SO}_{3} \mathrm{CF}_{3}\right)_{2}$ recorded in $n$-heptane at a concentration of $1.1 \times 10^{-5}$ $\mathrm{mol} / \mathrm{L}$ in the range temperature of (a) 293-343 K; (b) 343-293 K; (c) Thermal dependence of the absorbance at $530 \mathrm{~nm}$ in the cooling (red) and heating (black) modes for $\left[\mathrm{Fe}(\mathrm{Rtrz})_{3}\right]\left(\mathrm{SO}_{3} \mathrm{CF}_{3}\right)_{2}$. 
when the temperature was turned back to low temperature again (Fig. 3c).
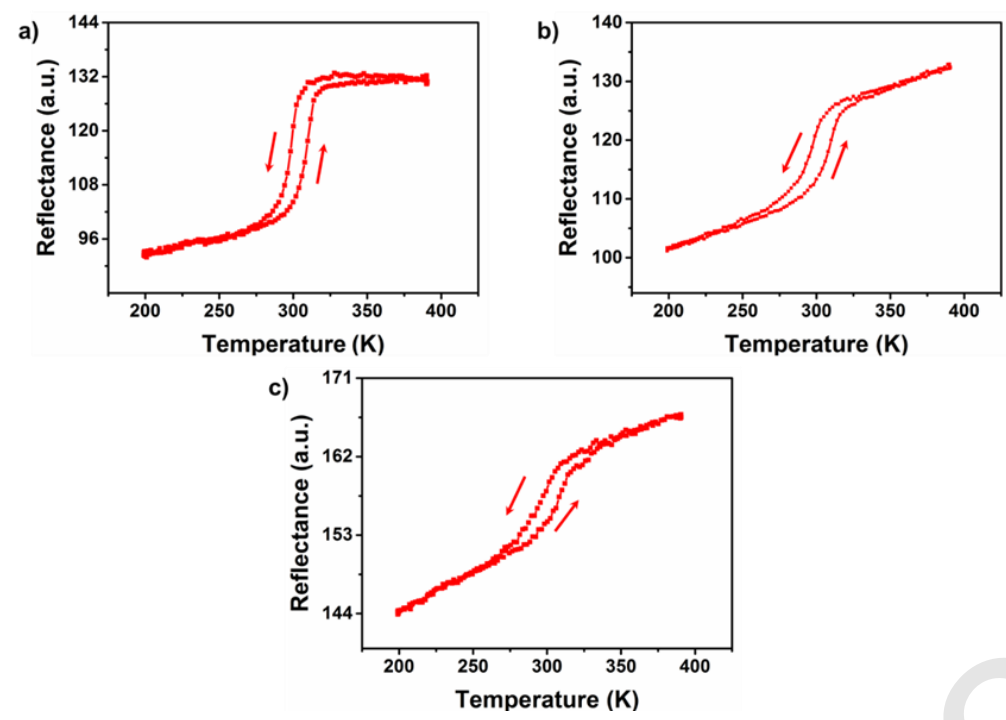

Fig. 4 Optical reflectivity measurements of dehydrated (a) bulk sample; (b) sample 1 (assembled in $n$-hexane, $0.1 \% \mathrm{w} / \mathrm{v}$ ); (c) sample 3 (assembled in cyclohexane, $0.1 \% \mathrm{w} / \mathrm{v}$ ). Note: heating or cooling rate: $10 \mathrm{~K} \cdot \mathrm{min}^{-1}$.

Moreover, optical reflectance of $\left[\mathrm{Fe}(\mathrm{Rtrz})_{3}\right]\left(\mathrm{SO}_{3} \mathrm{CF}_{3}\right)_{2}$ varying with temperature cycled between $200 \mathrm{~K}$ and $390 \mathrm{~K}$ was recorded. For the bulk sample (Fig. 4a), the transition temperatures were $T_{1 / 2(\downarrow)}=298 \mathrm{~K}$ and $T_{1 / 2(\uparrow)}=309 \mathrm{~K}$. A narrow hysteresis centered at room temperature was observed. This result was consistent with the data of variable-temperature UV-Vis. As shown in Fig. 4b and Fig. 4c, the transition became gradual and the transition temperatures were centered at $302 \mathrm{~K}$ for sample 1 with fiber network structure, while $301 \mathrm{~K}$ for the sample 3 with cubic structure. From these results, it can be concluded that as-synthesized $\left[\mathrm{Fe}(\mathrm{Rtrz})_{3}\right]\left(\mathrm{SO}_{3} \mathrm{CF}_{3}\right)_{2}$ nanomaterials showed excellent thermochromic behavior and room temperature spin transition.

In order to further confirm the SCO property of as-synthesized $\left[\mathrm{Fe}(\mathrm{Rtrz})_{3}\right]\left(\mathrm{SO}_{3} \mathrm{CF}_{3}\right)_{2}$, the magnetic measurements were performed. As shown in Fig. 5 (black) for the bulk sample, the value of $\chi_{\mathrm{m}} T$ ca. $3.5 \mathrm{~cm}^{3} \cdot \mathrm{K} \cdot \mathrm{mol}^{-1}$ at high temperature corresponded well to Fe(II) complex in the high spin state. While at $169 \mathrm{~K}$, the value of $0.08 \mathrm{~cm}^{3} \cdot \mathrm{K} \cdot \mathrm{mol}^{-1}$ indicated that the sample could fully transfer to low spin state. The transition temperatures were $T_{1 / 2(\downarrow)}=306 \mathrm{~K}$ and $T_{1 / 2(\uparrow)}=312 \mathrm{~K}$, and the hysteresis width was $6 \mathrm{~K}$. As shown in Fig. 5 (red), the spin transition of sample 1 became rather gradual accompanying residual 
HS fraction and also some residual LS fraction together with an apparent hysteresis loop. While for the nano-cubic structure sample 3 in Fig. 5 (blue), the spin transition was also around room temperature, and the hysteresis width increased. Consistent with the results in optical reflectivity measurements, herein the hysteresis loop was confirmed again for the nano-cubic structure of $\left[\mathrm{Fe}(\mathrm{Rtrz})_{3}\right]\left(\mathrm{SO}_{3} \mathrm{CF}_{3}\right)_{2}$. These results clearly demonstrated that $\left[\mathrm{Fe}(\mathrm{Rtrz})_{3}\right]\left(\mathrm{SO}_{3} \mathrm{CF}_{3}\right)_{2}$ nanomaterials presented obvious size dependent SCO property. As the size of SCO materials decreased to nano-scale, the surface-tovolume ratio increased, and the amount of inactive SCO residue on the surface of the complex increased, which resulted in the formation of high residual LS fraction. While the increased hysteresis width for $\left[\mathrm{Fe}(\mathrm{Rtrz})_{3}\right]\left(\mathrm{SO}_{3} \mathrm{CF}_{3}\right)_{2}$ nanomaterials could mainly be attributed to the intermolecular van der Waals interactions between the introduced tris(dodecyloxy)-benzamide structure. Besides, increased elastic interactions between SCO nanoparticles might also contribute the appreciated large hysteresis loop. In addition, water fraction in the complexs has no effect on the the spin transition behavior. It should be due 
to the introduction of tris(dodecyloxy)-benzamide, which could screen water away the iron center.

The room temperature spin transition behaviour was also confirmed by the calorimetric studies of the bulk and nano-sized samples. The calorimetric data was recorded in the heating and cooling modes at $10 \mathrm{~K} \cdot \mathrm{min}^{-1}$ in order to evaluate the enthalpy $(\Delta H)$ and entropy $(\Delta S)$ variations associated with the spin

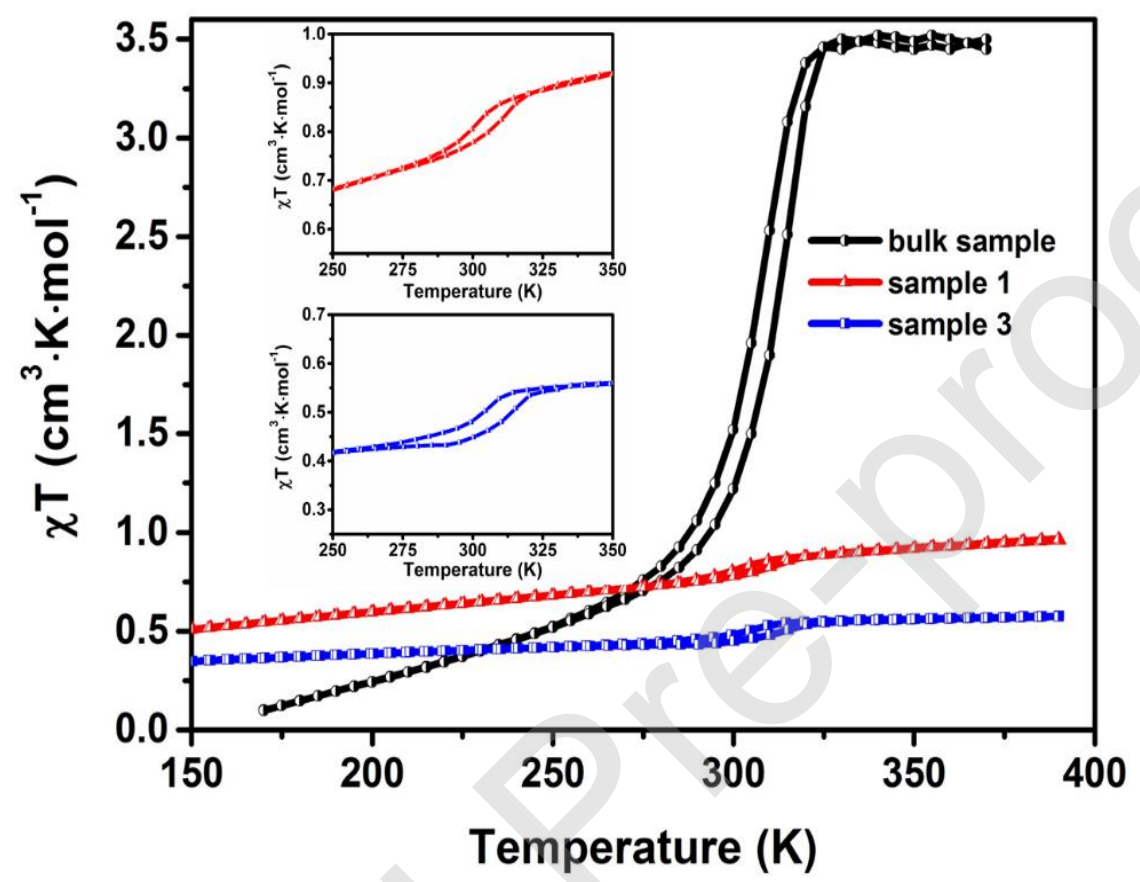

Fig. 5 Magnetic measurements of dehydrated bulk sample (black); sample 1 (red, assembled in $n$-hexane, $0.1 \%$ $w / v$ ); sample 3 (blue, assembled in cyclohexane, $0.1 \% w / v$ ). The inset shows a zoom in the SCO region.

transitions. DSC studies (Fig. S11) showed a singularity at $293 \mathrm{~K}$ and $313 \mathrm{~K}$ for the nano-sized sample 3. Compared with the magnetic measurement, the deviation of the transition temperature might be related to the difference of heating and cooling rates $\left(2 \mathrm{~K} \cdot \mathrm{min}^{-1}\right.$ for magnetic measurements and $10 \mathrm{~K} \cdot \mathrm{min}^{-}$ ${ }^{1}$ for DSC). The estimated $\Delta H$ and $\Delta S$ variations measured in the sample 3 were $13.9 \mathrm{~kJ} \cdot \mathrm{mol}^{-1}$ and $45.9 \mathrm{~J} \cdot \mathrm{mol}^{-1} \cdot \mathrm{K}^{-1}$, respectively. These values were at the same range as that of other Fe(II) SCO complex were found in gradual-type systems. $^{44}$

With the aim to determine more precisely the fraction of iron centres involved in the spin transition, ${ }^{57} \mathrm{Fe}$ Mössbauer spectra (Fig. S12) were recorded. Taking into account the low percentage of iron (lower than 3\%), only 
the spectrum for the bulk sample at $293 \mathrm{~K}$ was obtained. As expected, at $293 \mathrm{~K}$ the spectrum consists of one doublet with an isomeric shift of $1.29 \mathrm{mms}^{-1}$ and a quadruple splitting of $3.09 \mathrm{mms}^{-1}$ attributed to the HS state and two doublets with an isomeric shift of $0.40 \mathrm{mms}^{-1}$ and a quadruple splitting of $0.226 \mathrm{mms}^{-1}$ attributed to the LS state, in agreement with the magnetic data.

\section{Conclusion}

In summary, novel SCO nanomaterials featured with room temperature transition were prepared through the supramolecular gel strategy. The SCO derivative $\left[\mathrm{Fe}(\mathrm{Rtrz})_{3}\right]\left(\mathrm{SO}_{3} \mathrm{CF}_{3}\right)_{2}$ could form gels in alkane solvents, and the CGCs of the gels were $0.4 \% w / v$ for $n$-hexane, $0.4 \% w / v$ for $n$-heptane and $0.7 \% w / v$ for cyclohexane, respectively. Nanomaterials with different morphologies, including fiber network structure, lamellar shape and cubic structure, could be obtained by varying the concentrations of the gelators and the temperature of the solution. Intriguingly, as-prepared $\left[\mathrm{Fe}(\mathrm{Rtrz})_{3}\right]\left(\mathrm{SO}_{3} \mathrm{CF}_{3}\right)_{2}$ nanomaterials presented room temperature transition with a hysteresis loop. The unique SCO property of nanomaterials may be envisaged as possessing potential applications in display devices, inkless paper and micro electro mechanical systems. The approach presented herein should be applicable for preparation of an extended range of SCO nanomaterials.

\section{Conflicts of interest}

There are no conflicts to declare.

\section{Author Contributions}

\# Xuan An and Wan Fang contributed equally to this work. 


\section{Credit author statement}

Haonan Peng, Yu Fang and Lionel Salmon conceived the experiments, supervised the research work, and wrote the paper. Xuan An and Wan Fang synthesized the complex, and carried out the sample characterization and helped analyzing the data and writing manuscript. Zhaolong Wang and Kaiqiang Liu performed the TEM measurements, and helped to conduct some experimental works. Liping Ding, Junxia Peng and Taihong Liu helped to analyze the data and writing the manuscript. All authors contributed to the interpretation of the results, and have given approval to the final version of the manuscript.

\section{Declaration of interests}

The authors declare that they have no known competing financial interests or personal relationships that could have appeared to influence the work reported in this paper.

\section{Acknowledgements}

This work was supported by the National Natural Science Foundation of China (No. 21603138, 21972084 and 21820102005), the Fundamental

Research Funds for the Central Universities (No. GK202005002, GK202001005 and GK202003040), 111 project (B14041) and Program for Changjiang Scholars and Innovative Research Team in University (IRT-14R33). We also appreciate the support from "The Youth Innovation Team of Shaanxi Universities". 


\section{References}

1 A. Bousseksou, G. Molnár, L. Salmon and W. Nicolazzi, Chem. Soc. Rev., 2011, 40, 3313.

2 H. Li and H. Peng, Curr. Opin. Colloid Interface Sci., 2018, 35, 9.

3 Francisco-Javier Valverde-Muñoz, M. Seredyuk, M. C. Muñoz, G. Molnár, Y. S. Bibik, and J. A. Real, Angew. Chem. Int. Ed., 2020, 59, 2.

4 J. Dugay, M. Giménez-Marqués, T. Kozlova, H. W. Zandbergen, E. Coronado and H. S. J. van der Zant, Adv. Mater., 2015, 27, 1288.

5 A. Benchohra, C. Méthivier, J. Landoulsi, D. Kreher, and R. Lescouëzec, Chem. Commun., 2020, 56, 6587.

6 K. S. Kumar and M. Ruben, Coord. Chem. Rev., 2017, 346, 176.

7 A. Tissot, X. Kesse, S. Giannopoulou, I. Stenger, L. Binet, E. Rivière and C. Serre, Chem. Commun., 2019, 55, 194.

8 C. Jureschi, J. Linares, A. Boulmaali, P. R. Dahoo, A. Rotaru and Y. Garcia, Sensors, 2016, 16, 187.

9 C. Bartual-Murgui, A. Akou, C. Thibault, G. Molnár, C. Vieu, L. Salmon and A. Bousseksou, J. Mater. Chem. C, 2015, 3, 1277.

10M. D. Manrique-Juárez, F. Mathieu, A. Laborde, S. Rat, V. Shalabaeva, P. Demont, O. Thomas, L. Salmon, T. Leichle, L. Nicu, G. Molnár and A. Bousseksou, Adv. Funct. Mater., 2018, 28, 1801970.

11S. Rat, M. Piedrahita-Bello, L. Salmon, G. Molnár, P. Demont and A.

Bousseksou, Adv. Mater., 2018, 30, 1705275.

12G. Molnár, S. Rat, L. Salmon, W. Nicolazzi and A. Bousseksou, Adv. Mater., 2018, 30, 17003862.

13M. Mikolasek, M. D. Manrique-Juarez, H. J. Shepherd, K. Ridier, S. Rat, V. Shalabaeva, A. Bas, I. E. Collings, F. Mathieu, J. Cacheux, T. Leichle, L. Nicu, W. Nicolazzi, L. Salmon, G. Molnár and A. Bousseksou, J. Am. Chem. Soc., 2018, 140, 8970.

14S. Liu, K. Zhou, T. Yuan, W. Lei, H. Chen, X. Wang and W. Wang, J. Am. Chem. Soc., 2020, 142, 15852. 
15M. Seredyuk, Ana B. Gaspar, V. Ksenofontov, S. Reiman, Y. Galyametdinov,

W. Haase, E. Rentschler, and P. Gütlich, Chem. Mater., 2006, 18, 2513.

16M. Seredyuk, A. B. Gaspar, V. Ksenofontov, Y. Galyametdinov, M.

Verdaguer, F. Villain, and P. Gütlich, Inorg. Chem., 2008, 47, 10232.

17L. Salmon and L. Catala, C. R. Chim., 2018, 21, 1230.

18T. Delgado, C. Enachescu, A. Tissot, A. Hauser, L. Guénée and C. Besnard, J. Mater. Chem. C, 2018, 6, 12698.

19J. Larionova, L. Salmon, Y. Guari, A. Tokarev, K. Molvinger, G. Molnár and A. Bousseksou, Angew. Chem. Int. Ed., 2008, 47, 8236.

20O. Klimm, C. Göbel, S. Rosenfeldt, F. Puchtler, N. Miyajima, K. Marquardt, M. Drechsler, J. Breu, S. Förster and B. Weber, Nanoscale, 2016, 8, 19058.

21 H. Peng, G. Molnár, L. Salmon and A. Bousseksou, Eur. J. Inorg. Chem., 2015, 20, 3336.

22H. Peng, G. Molnár, L. Salmon and A. Bousseksou, Chem. Commun., 2015, 51, 9346.

23C. Bartual-Murgui, E. Natividad and O. Roubeau, J. Mater. Chem. C, 2015, 3, 7916.

24M. Giménez-Marqués, M. L. García-Sanz de Larrea and E. Coronado, $J$.

Mater. Chem. C, 2015, 3, 7946.

25 A. Tokarev, L. Salmon, Y. Guari, W. Nicolazzi, G. Molnár and A.

Bousseksou, Chem. Commun., 2010, 46, 8011.

26H. Hagiwara and S. Okada, Chem. Commun., 2016, 52, 815.

27 J. E. Clements, J. R. Price, S. M. Neville and C. J. Kepert, Angew. Chem. Int. Ed., 2016, 55, 15105.

28S. Hayami, Z. G., H. Yoshiki, A. Fujishima and O. Sato, J. Am. Chem. Soc., 2001, 123, 11644.

29S. Murata, K. Takahashi, T. Mochida, T. Sakurai, H. Ohta, T. Yamamoto and Y. Einaga, Dalton Trans., 2017, 46, 5786.

30 A. Sarkar, R. Sasmal, C. Empereur-mot, D. Bochicchio, S. V. K. Kompella, K. Sharma, S. Dhiman, B. Sundaram, S. S. Agasti, G. M. Pavan, and S. J. George, J. Am. Chem. Soc., 2020, 142, 7606.

31 M. Hecht, B. Soberats, J. Zhu, V. Stepanenko, S. Agarwal, A. Greiner and F. Würthner, Nanoscale Horiz., 2019, 4, 169. 
32R. Yamamoto, Y. Minami, J. K.-H. Hui, Masa-aki Morikawa, and N.

Kimizuka, J. Am. Chem. Soc., 2020, 142, 1424.

33S. R. Jadhav, P. K. Vemula, R. Kumar, S. R. Raghavan and G. John, Angew.

Chem. Int. Ed., 2010, 49, 7695.

34M. E. Cooke, S. W. Jones, B. Horst, N. Moiemen, M. Snow, G. Chouhan, L.

J. Hill, M. Esmaeli, R. J. A. Moakes, J. Holton, R. Nandra, R. L. Williams,

A. M. Smith and L. M. Grover, Adv. Mater., 2018, 30, 1705013.

35O. Roubeau, A. Colin, V. Schmitt and R. Clérac, Angew. Chem. Int. Ed., 2004, 43, 3283.

36T. Fujigaya, D. Jiang, and T. Aida, Chem. Asian J., 2007, 2, 106.

37S. Brooker, Chem. Soc. Rev., 2015, 44, 2880.

38D. Rosario-Amorin, P. Dechambenoit, A. Bentaleb, M. Rouzières, C.

Mathonière and R. Clérac, J. Am. Chem. Soc., 2018, 140, 98.

39T. Fujigaya, D. Jiang, and T. Aida, J. Am. Chem. Soc., 2003, 125, 14690.

40T. Fujigaya, D. Jiang, and T. Aida, J. Am. Chem. Soc., 2005, 127, 5484.

41 A. Grosjean, N. Daro, B. Kauffmann, A. Kaiba, J.- F. Létard and P.

Guionneau, Chem. Commun., 2011, 47, 12382.

42M. A. Shcherbina, A. V. Bakirov, A. N. Yakunin, U. Beginn, L. Yan, M.

Möller and S. N. Chvalun, Soft Matter, 2014, 10, 1746.

43 K. Köhler, G. Förster, A. Hauser, B. Dobner, U. F. Heiser, F. Ziethe, W.

Richter, F. Steiniger, M. Drechsler, H. Stettin and A. Blume, J. Am. Chem.

Soc., 2004, 126, 16804.

44 O. Roubeau, M. Castro, R. Burriel, J. G. Haasnoot and J. Reedijk, J. Phys.

Chem. B, 2011, 115, 3003. 
Table 1 Gelation behavior of $\left[\mathrm{Fe}(\mathrm{Rtrz})_{3}\right]\left(\mathrm{SO}_{3} \mathrm{CF}_{3}\right)_{2}$ in different solvents at a concentration of $2.0 \%(w / v)$ at $283 \mathrm{~K}$ and CGCs (\%; in parentheses)

\begin{tabular}{cccc}
\hline Solvent & Observation & Solvent & Observation \\
\hline $\mathrm{CH}_{2} \mathrm{Cl}_{2}$ & $\mathrm{PS}$ & $n$-Pentane & $\mathrm{PG}$ \\
$\mathrm{CHCl}_{3}$ & $\mathrm{~S}$ & $n$-Hexane & $\mathrm{G}(0.4 \%)$ \\
$\mathrm{CCl}_{4}$ & $\mathrm{~S}$ & $n$-Heptane & $\mathrm{G}(0.4 \%)$ \\
Acetone & $\mathrm{TS}$ & $n$-Octane & $\mathrm{PG}$ \\
Benzene & $\mathrm{S}$ & Cyclohexane & $\mathrm{G}(0.7 \%)$ \\
Toluene & $\mathrm{S}$ & Petroleum ether & $\mathrm{PG}$ \\
Paraxylene & $\mathrm{S}$ & Acetonitrile & $\mathrm{I}$ \\
THF & $\mathrm{S}$ & Methanol & $\mathrm{I}$ \\
Ethyl acetate & $\mathrm{I}$ & Isopropanol & $\mathrm{TS}$ \\
\hline
\end{tabular}

Note: $\mathrm{S}=$ Solution; $\mathrm{TS}=$ Turbid solution; $\mathrm{I}=$ Insoluble $\mathrm{G}=\mathrm{Gel} ; \mathrm{PG}=$ Partial gel; $\mathrm{PS}=$ Partial solution . 